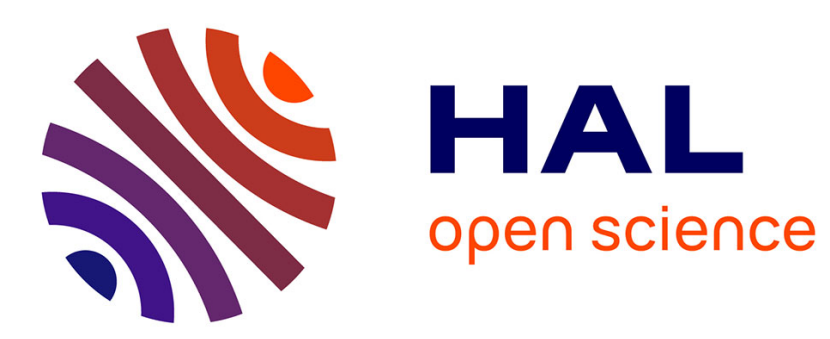

\title{
Counterproductive Environmental Performance Displays: Lessons from the Automotive Sector
}

Béatrice Parguel, Florence Benoît-Moreau

\section{To cite this version:}

Béatrice Parguel, Florence Benoît-Moreau. Counterproductive Environmental Performance Displays: Lessons from the Automotive Sector. EMAC Conference, May 2013, Turkey. halshs-00948940

\section{HAL Id: halshs-00948940 \\ https://shs.hal.science/halshs-00948940}

Submitted on 26 Feb 2014

HAL is a multi-disciplinary open access archive for the deposit and dissemination of scientific research documents, whether they are published or not. The documents may come from teaching and research institutions in France or abroad, or from public or private research centers.
L'archive ouverte pluridisciplinaire HAL, est destinée au dépôt et à la diffusion de documents scientifiques de niveau recherche, publiés ou non, émanant des établissements d'enseignement et de recherche français ou étrangers, des laboratoires publics ou privés. 


\title{
Counterproductive Environmental Performance Displays: Lessons from the Automotive Sector
}

\author{
Béatrice Parguel * \\ Chercheure CNRS, DRM UMR CNRS 7088, Université Paris-Dauphine
}

Florence Benoît-Moreau

Maître de Conférences, DRM UMR CNRS 7088, Université Paris-Dauphine

\begin{abstract}
:
Using classical models of information processing and persuasion, this study examines the efficiency of European Directive 1999/94/EC, pertaining to automotive carbon emission information, as a means to encourage more sustainable consumption patterns. The Directive requires European carmakers to display their vehicles' carbon emissions prominently in advertisements. An experiment conducted with a representative sample of consumers reveals that this obligation is counterproductive among non-expert consumers. The display of environmental information might have better effects if it were to use a color-coded grading scale to help them. Beyond this recommendation, the authors discuss some implications for public policy makers.
\end{abstract}

Key Words: environmental labeling, sustainable consumption, consumer information, brand image, public policy.

Track: Consumer protection 


\section{Introduction}

In compliance with the Kyoto protocol's targeted 8\% reduction of greenhouse gas emissions by 2012, the European Directive 1999/94/EC of December 13, 1999, focused on passenger cars as the primary source of carbon emissions and required information regarding the carbon emissions of new passengers cars sold in European countries "to be easy to read and no less prominent than the main part of the information" at the point of sale and in all printed promotional material.

The present research addresses the question of the directive's efficacy to foster sustainable consumption patterns. Is raw information about carbon emissions sufficient to enlighten consumers, even supposing that everyone notices and reads it? Lessons from the European experience thus might help define efficient public policy worldwide.

To do so, we begin by establishing a conceptual framework based on theories of information processing and persuasion, which we test through an experimental approach. The results indicate that Directive 1999/94/EC is counterproductive for consumers who lack sufficient knowledge about carbon emissions standards - approximately three-quarters of the population in our sample. The appearance of carbon emission information in advertising improves consumers' perceptions of the automaker's ecological image, even when that information indicates poor environmental performance (EP). The color-coded, A-G format label would be more effective.

\section{Literature Review}

Because some proportion of damage to the environment is due to consumers' lifestyles, the 1992 UN summit in Rio introduced the notion of "sustainable consumption," as a top priority. The Oslo Symposium on Sustainable Consumption (1994) defends a privileged path consisting in empowering consumers with relevant knowledge to achieve new consumption patterns through responsible and informed choices (Scammon and Mayer, 1993). However, consumers are constrained by the availability of relevant information about alternative options, by their limited financial, time, cognitive capacity, and knowledge resources, as well as by their perceived lack of self-efficacy, which reduces their motivation to behave responsibly. Labeling schemes attempt to counter the problem of a lack of relevant information, as exemplified by nutrition labels, eco-labels, energy labels, and emerging carbon footprint labels. A few works address the efficacy of eco-labels (Langer, Eisend and Kuß, 2008). To extend these previous contributions, we address a mandatory scheme (European Directive 1999/94/EC), which requires the display of self-declared, single-criterion information: the carbon emission rate of each vehicle. Conceptually, we build on the observation that consumers suffer from limited resources in their opportunity, motivation, and ability to consider information, which implies that the elaboration likelihood model (ELM; Petty and Cacioppo, 1981) should be relevant for understanding the efficacy of the directive.

\section{Conceptual Framework and Hypotheses}

The ELM framework identifies different routes to persuasion, depending on people's motivation and ability to consider the information provided by a persuasive message. In our study, the objective information (i.e., carbon emission rate) demands specific expertise to be processed efficiently, so we predict that the display of emission rates exerts different influences on consumers, depending on their degree of expertise.

For expert consumers, we predict that the European Directive will exert the desired influence: If they remember having seen an emission rate, without remembering the value, the mention should have no effect, whereas if they remember a high emission rate, they will perceive the brand as less ecological. However, among non-expert consumers who recall having seen the 
emission rate, the effect of the display may be the same, regardless of whether they remember the value or not, because they cannot accurately assess the data. In line with the ELM predictions, these latter consumers likely use heuristics, such as metacognition about advertising practices (Wright, 2002), to interpret the presence of the carbon emission rate, which ultimately will exert an influence on how they perceive the brand.

Inman, McAlister, and Hoyer (1990) demonstrate a similar signal effect in the case of sales promotions: When consumers adopt the peripheral route, the mere signal of a promotion is enough to trigger buying behavior, even without a price discount. We thus predict that consumers explain the display of the carbon emission rate by assuming the advertiser (i.e., carmaker) is proud of its EP, supported by their generalized metacognition that advertising exists to provide positive information about the product or brand (Wright, 2002). The reasoning leads to our first hypothesis:

$H_{1}$ : Among non-expert consumers, the display of a poor EP indicator enhances the brand's ecological image, whether these consumers (a) remember its value or (b) not.

The information format also determines information efficacy. At a general level, cognitive psychology indicates the superiority of visual versus textual communication in terms of recall and memory (Paivio, 1969). In an advertising context, Childers and Houston (1984) show that this superiority is especially prominent among consumers with low motivation and ability to process the semantic content of messages. A similar case appears in research into nutrition labels, which also display numerical information from which consumers must infer nutritional qualities. Central to the processing of numerical nutrition information is the need for a comparison baseline, because raw figures offer no real meaning on their own and instead must be confronted against reference values. For consumers with low literacy levels, graphic nutrition labels (e.g., showing value ranges or ratings) are more effective than those displaying raw figures or percentages in terms of aiding consumers' judgment (Viswanathan, Hastak and Gau, 2009). Our carbon emission information context seems similar; adding a graphic representation of the raw information about emission rates should help non-expert consumers calibrate EP information. Therefore, we hypothesize

$\mathrm{H}_{2}$ : Among non-expert consumers, the addition of a graphic A-G scale to a poor EP indicator damages the brand's ecological image.

Previous advertising research also uses a mediation chain, from attitude toward the ad to brand attitude, through brand beliefs (Lutz, 1985), to explain advertising effectiveness. We predict this effect applies in our study context too, such that providing EP information influences brand attitudes. According to the ELM model, experts and non-experts do not follow the same mediation route though. For non-expert consumers, the first causal factor is the format of EP information (raw or graphic); they cannot interpret the value of EP indicators by themselves. Therefore,

$H_{3}$ : Among non-expert consumers who view a poor EP indicator, the brand's ecological image mediates the influence of the EP information format (a), but not of the actual value of the EP indicator (b) on brand attitude.

\section{Methodology}

The experimental design consists of a 4 (no rate; carbon emission rate slightly above the norm; very high carbon emission rate; graphic environmental label) by 2 (experts versus nonexperts) between-subjects design, in which we manipulated environmental information. We measured respondents' objective expertise.

The average carbon emission rate required for all new passenger cars by 2015 by the European Automobile Manufacturers Association agreement is $130 \mathrm{~g} / \mathrm{km}$; therefore, we consider $149 \mathrm{~g} / \mathrm{km}$ a rate slightly above the norm and $209 \mathrm{~g} / \mathrm{km}$ as a very high carbon emission rate. We 
used the two above-norm values to identify any potential threshold effects. The manipulation check confirmed that respondents perceived the latter as higher than the former $(M=3.66, M$ $=4.69, \mathrm{p}<.01)$. In all conditions, respondents reviewed a commercial Web page, which presented a new vehicle (L3) constructed by the brand LUNA, a fictitious manufacturer. Then, they completed the questionnaire.

To ensure a statistically generalizable sample, we recruited 422 respondents (51\% women, mean age $=38$ years) from the panel of a professional market research institute. We randomly assigned the subjects to the four treatments.

To assess brand ecological image, we developed a four-item ad hoc scale. The rest of the questionnaire contained adaptations of previously validated scales: attitudes toward the brand (Batra et al., 2000) and web page (Ng and Chyi, 2008), consumers' automobile involvement (Strazzieri, 1994), and environmental consciousness (authors, 2011). To measure respondents' objective expertise, we assessed their knowledge of the average carbon emission required for all new passenger cars by 2015 by the European Automobile Manufacturers Association agreement. The mean item scores indicated the construct measures. In Appendix 2, we provide the scale items, means, and standard deviations for each experimental treatment.

\section{Results}

Of the 422 respondents surveyed, some did not support the manipulation, such that they recalled being exposed to a rate when they were not or vice versa. Some did not remember the exact rate even if they recalled being exposed to a rate display (55 respondents) or provided the wrong answer (39 respondents). Therefore, 270 people remained in the sample to test $\mathrm{H}_{1}$, and 215 respondents qualified to test $\mathrm{H}_{2}$ and $\mathrm{H}_{3}$. Non-experts represented $72 \%$ and $74 \%$ of these samples, respectively. Additional analyses showed that the four samples were homogenous in terms of their expertise $\left(\chi^{2}(2)=2.82\right.$, ns), environmental consciousness $(\mathrm{F}(3,214)=.58, \mathrm{~ns})$, and automobile involvement $(\mathrm{F}(3,214)=1.08, \mathrm{~ns})$.

To test our hypotheses, we ran analyses of variance, controlling for respondents' attitudes toward the brand, automobile involvement, environmental consciousness, gender, and age. We present the results in Table 1.

Table 1. Influences of Environmental Information on Non-Expert Consumers No Memory of $\mathrm{CO}_{2}$ Emissions Memory of $\mathrm{CO}_{2}$ Emissions Rate Rate

\begin{tabular}{llll}
\hline $\mathrm{CO}_{2}$ emissions rate (no display vs. display) & $12.72^{* * *}$ & \\
\hline $\mathrm{CO}_{2}$ emissions rate (no display vs. 149g/km vs. & & $5.62^{* * *}$ \\
$209 \mathrm{~g} / \mathrm{km})$ & & $10.02^{* * *}$ \\
\hline $\mathrm{A}-\mathrm{G}$ environmental label (no display vs. display) & & $11.18^{* * *}$ & $9.20^{* * *}$ \\
\hline Attitude toward the ad & $8.69^{* * *}$ & $7.35^{* * *}$ & .21 \\
\hline Automobile involvement & $12.06^{* * *}$ & .21 & .88 \\
\hline Environmental consciousness & $10.49^{* * *}$ & $5.02^{* * *}$ & .88 \\
\hline Gender & 1.26 & 2.70 & .26 \\
\hline Age & .75 & $.28^{* * *}$ & $.21 * * *$ \\
\hline Adjusted $\mathrm{R}^{2}$ & $.54 * * *$ & & \\
\hline
\end{tabular}

$* * * p<.01$ (two-tailed).

The non-expert consumers who remembered the display but not the rate value perceived the carmaker brand as more ecological $\left(\mathrm{M}_{\text {ecolo }}=4.97 ; \mathrm{F}(1,61)=12.72, \mathrm{p}<.05\right)$ than non-experts who were not exposed to such information $\left(\mathrm{M}_{\mathrm{ecolo}}=4.16\right)$. Furthermore, recalling the value of 
the carbon emissions rate influenced their perceptions of the carmaker's ecological image $(\mathrm{F}(2,104)=5.62, \mathrm{p}<.05)$, such that they perceived the carmaker brand as less ecological when they saw no information about the emission rate $\left(M_{\text {ecolo }}=4.12\right)$ than when they remembered a $149 \mathrm{~g} / \mathrm{km}$ emission rate $\left(\mathrm{M}_{\text {ecolo }}=5.11 ; \mathrm{F}(1,75)=16.19\right.$, p <.05) or a $209 \mathrm{~g} / \mathrm{km}$ emission rate $\left(\mathrm{M}_{\text {ecolo }}=4.41 ; \mathrm{F}(1,78)=.57, \mathrm{~ns}\right)$. These results support $\mathrm{H}_{1 \mathrm{a}}$ and $\mathrm{H}_{1 \mathrm{~b}}$. In addition, all else being equal (i.e., the same $149 \mathrm{~g} / \mathrm{km}$ carbon emission rate), adding a color-coded (green-to-red) environmental label $\left(\mathrm{M}_{\mathrm{ecolo}}=5.05\right)$ to the display of a moderately high carbon emission rate $\left(\mathrm{M}_{\mathrm{ecolo}}=4.06\right)$ damaged the carmaker's ecological image among non-expert consumers $(\mathrm{F}(1,80)=10.02, \mathrm{p}<.05)$, in support of $\mathrm{H}_{2}$.

As ancillary findings, we also noted the results for a similar analysis among expert consumers. Two main differences emerged. First, recall of the carbon emissions display without memory of the carbon emissions rate did not influence their perceptions of the carmaker's ecological image $(\mathrm{F}(1,20)=.18, \mathrm{~ns})$. Second, adding a green-to-red environmental label to the display of a high carbon emission rate did not influence their perceptions either $(\mathrm{F}(1,28)=1.03$, ns $)$. The only factor that influenced this perception was their recall of the value of the carbon emissions rate $(\mathrm{F}(2,31)=12.83 ; \mathrm{p}<.05)$. That is, expert consumers perceived the carmaker brand as more ecological when it provided no emission rate information $\left(\mathrm{M}_{\mathrm{ecolo}}=4.34\right)$ than when they remembered the $149 \mathrm{~g} / \mathrm{km}$ emission rate $\left(\mathrm{M}_{\text {ecolo }}=4.15 ; \mathrm{F}(1,25)=.13\right.$, $\left.\mathrm{ns}\right)$ or $209 \mathrm{~g} / \mathrm{km}$ emission rate $\left(\mathrm{M}_{\text {ecolo }}=2.04 ; \mathrm{F}(1,25)=19.28, \mathrm{p}<.05\right)$.

To test the mediating influence of the brand's ecological image on the link between EP information display and consumers' attitudes toward the brand, we used Zhao, Lynch and Chen's (2010) procedure and Hayes's (2012) PROCESS macro. We applied a bootstrapping procedure with 5000 bootstrapped samples to counteract the assumption of normality for the sampling distribution of the indirect effect (ab), as required by the Sobel test (Hayes 2009).

Table 2. Mediation Tests: Bootstrap Results for Indirect Effects

\begin{tabular}{lcccc}
\hline $\begin{array}{l}\text { Indirect Effect on Brand } \\
\text { Attitude }\end{array}$ & $\begin{array}{c}\text { Mean } \\
\text { Indirect } \\
\text { Effect }(\boldsymbol{a b} \\
\text { paths })\end{array}$ & $\begin{array}{c}\text { Path from } \\
\text { Environmental } \\
\text { Information to } \\
\text { Mediator }\end{array}$ & $\begin{array}{c}\text { Path from } \\
\text { Mediator to } \\
\text { Brand Attitude }\end{array}$ & $\begin{array}{c}\text { Bias-Corrected } \\
\text { 95\%fidence } \\
\text { Interval }\end{array}$ \\
\hline $\begin{array}{l}\text { Brand ecological image } \\
\text { mediating the effect of } \\
\text { environmental information } \\
\text { format }\end{array}$ & $\mathbf{- . 2 5 5 4}$ & $\mathbf{- . 9 3 3 5}$ & $\mathbf{. 2 7 3 6}$ & {$[-.5249 ;-\mathbf{0 9 2 1}]$} \\
$\begin{array}{l}\text { Brand ecological image } \\
\text { mediating the effect of } \\
\text { environmental performance }\end{array}$ & -.1586 & -.6020 & $\mathbf{. 2 6 3 5}$ & {$[-.6596 ; .0208]$} \\
\hline
\end{tabular}

Notes: Significant effects at a 95\% confidence interval appear in bold.

As the results in Table 2 indicate, considering the influence of the environmental performance information value (i.e., $149 \mathrm{~g} / \mathrm{km}$ vs. $209 \mathrm{~g} / \mathrm{km}$ ) on brand attitude, the bootstrap analysis showed no significant indirect effect. However, considering the influence of environmental information format (i.e., $149 \mathrm{~g} / \mathrm{km}$ with or without a green-to-red environmental label), the bootstrap analysis revealed that the mean indirect effect was negative and significant $(a b=-$ $.2554)$, and the $95 \%$ confidence interval did not include $0(-.5249$ to -.0921$)$. In the indirect path, $a=-.9335$ ( $\mathrm{p}<.05$ ), so adding the color-coded environmental label damaged brand ecological image by .9335 units, and $b=.2736$ ( $\mathrm{p}<.05$ ), so even when holding the environmental information format constant, a unit increase in brand ecological image enhanced brand attitude by .2736 units. The direct effect $c$ was not significant, so we can only establish indirect-only mediation. These results support $\mathrm{H}_{3 \mathrm{a}}$ and $\mathrm{H}_{3 b}$. 


\section{Discussion}

This study examines the effects of Directive 1999/94/EC. The most notable result is our finding of a counterproductive effect of the mandated information on non-expert consumers, who represent about three-quarters of the population. For these consumers, the display of the carbon emission rate falsely improves the company's ecological image, whether they remember the rate or not. A possible strategy to eliminate this bias would be to show, in addition to a raw environmental performance indicator, a graphic, red-to-green environmental label that enables non-experts to recognize when the label indicates EP and thus make more accurate brand ecological evaluations. This study also provides evidence of the mediation route to persuasion followed by non-expert consumers, in line with the ELM framework: EP information influences brand attitude through brand beliefs (brand ecological image), but it is not the value of the EP indicator per se that counts, but rather its format.

We thus draw several theoretical implications regarding consumers' information processing. The positive signal effect of displaying poor raw EP indicators is not surprising; Petty and Cacioppo (1981) clearly describe the peripheral route to persuasion as based on inferences or heuristics obtained from various elements of the communication (e.g., source, execution cues). What is interesting is the element that actually engenders the heuristic, namely, the carbon emission rate, which is an objective, technical piece of information that offers simple, unbiased evidence of a car's environmental quality. This finding could spark an interesting debate among ELM researchers about central (e.g., message and argument per se) and peripheral cues (e.g., music, source, graphical elements). In our study, it was not the element per se (the rate) that mattered but rather the way consumers processed it, depending on their ability. The EP indicator itself cannot constitute the central or peripheral element, in that it offers two distinct components: its value (processed by experts and therefore a central cue) and its format (raw vs. graphic; processed by non-experts and therefore a peripheral cue). Format is always a crucial element that public policy makers cannot ignore.

This research also provides insights about how people process numerical information, in line with recent research into nutrition labels (Viswanathan, Hastak and Gau, 2009). Graphic EP indicators lead to more accurate product evaluations. Such graphic presentations, which mix scales, colors, and numerical information, offer a compelling option for public policy makers, in the sustainability domain as well as nutrition settings. Further research must pursue a deeper theoretical understanding of their efficacy, perhaps based on psychometric theory (e.g., anchor points, number of anchors) or cultural approaches that detail labels' metaphorical roles in relation to other concrete objects (e.g., ruler or scale, speedometer, traffic lights).

From a public policy perspective, this study highlights the ineffectiveness of the European Directive, as it is currently applied, and suggests some corrections. More generally, we offer some insights about sustainable consumption public policies that rely on increasing consumer knowledge or information. First, very simple measures, such as showing an EP indicator, are not sufficient. Rather, they need to be accompanied by some education scheme, whether in brochures or legal footnotes, to explain the meaning of the figures. Second, we reveal that mere information, even at the most basic level, cannot be disconnected from its presentation or information format. Third, we believe it is possible to improve the process for defining public policy in Europe by introducing more experiments and intermediate field studies before proposing new regulations. Finally, we note several limitations of this study. It features only a French sample that, though representative of France, cannot represent all European citizens, especially in terms of their varying levels of environmental consciousness. In addition to replicating this experiment in other countries, researchers might replicate it using other carbon emissions values, to better understand the threshold or specific effects of certain numerical 
values (e.g., round vs. 9-ending numbers). A replication of this study with a well-known brand, rather than a fictitious one, also could complement our findings by indicating how the processes of persuasion and attitude change with previous brand beliefs in this context (Lutz, 1985).

\section{Bibliographie}

Authors (2011)

Batra R.V. Ramaswamy D.L.A., Steenkamp J-B.E.M. \& Ramachander S. (2000). Effects of brand local and nonlocal origin on consumer attitudes in developing countries. Journal of Consumer Psychology, 9, 2, 83-95.

Childers T.L. \& Houston M.J. (1984). Condition for a picture-superiority effect on consumer memory. Journal of Consumer Research, 11, 3, 643-654.

Hayes A.F. (2009). Beyond Baron and Kenny: statistical mediation analysis in the new millennium. Communication Monographs, 76, 4, 408-420.

Hayes A.F. (2012). PROCESS: A versatile computational tool for observed variable mediation, moderation, and conditional process modeling. Available at http://www.afhayes.com/public/process2012.pdf.

Inman J.J., McAlister L. \& Hoyer W.D. (1990). Promotion signal: Proxy for a price cut?. Journal of Consumer Research, 17, 1, 74-81.

Langer A., Eisend M. \& Kuß A. (2008). The impact of eco-labels on consumers: Less information, more confusion?". European Advances in Consumer Research, 8, 338339.

Lutz R.J. (1985). Affective and cognitive antecedents of attitude toward the ad: A conceptual framework. In L.F. Alvitt \& A.A. Mitchell (eds.). Psychological Processes and Advertising Effects, Hillsdale: Lawrence Erlbaum Associates.

Ng, V.W.K. \& H.I. Chyi (2008). The Effects of Context Clutter and Advertising Repetition on Attitudinal and Behavioral Changes toward an Online Advertisement. L. Leung, A. Fung, and P.S.N. Lee (eds.). Embedding into Our Lives: New Opportunities and Challenges of the Internet (pp.145-164). Hong Kong: Chinese University Press.

Paivio, A. (1969). Mental Imagery in Associative Learning and Memory. Psychological Review, 76, 3, 241-263.

Petty, R.E. \& J.T. Cacioppo (1981). Attitudes and Persuasion: Classic and Contemporary Approaches. Dubuque: W.C. Brown.

Scammon, D. \& R.N. Mayer (1993). Environmental Labeling and Advertising Claim: International Action and Policy Issues. European Advances in Consumer Research (pp.338-344). Provo UT: Association for Consumer Research.

Strazzieri A. (1994). Mesurer l'implication durable indépendamment du risque perçu. Recherche et Applications en Marketing, 9, 1, 73-91.

Viswanathan M., Hastak M. \& R. Gau (2009). Understanding and facilitating the usage of nutritional labels by low-literate consumers. Journal of Public Policy \& Marketing, 28, 3, 135-145.

Wright P. (2002). Marketplace metacognition and social intelligence. Journal of Consumer Research, 28, 4, 677-683.

Zhao X., Lynch J.G. Jr. \& Chen Q. (2010). Reconsidering Baron and Kenny: Myths and truths about mediation analysis. Journal of Consumer Research, 37, 3, 197-206. 